\title{
INVESTIGAR Y CURAR: CONOCIMIENTOS Y PROFILAXIS DEL BOCIO ENDÉMICO EN LA ARGENTINA (1916- 1958)
}

\author{
Adriana Feld \\ Universidad Nacional de San Martín-CONICET \\ Analía E. Busala \\ Universidad de Buenos Aires
}

\section{RESUMEN}

El presente trabajo se orienta a reconstruir el recorrido histórico de la producción de conocimiento, así como los debates acerca de la enfermedad del bocio endémico en Argentina, fundamentalmente entre 1916 y 1955. Tomando en cuenta aspectos sociales, políticos y materiales, el trabajo explora la resignificación del conocimiento científico y médico en términos de medidas de prevención y tratamiento de la salud, a través del posicionamiento de diversos actores sociales implicados y de diversos contextos históricos e institucionales.

PALABRAS CLAVE: Bocio endémico. Investigación científica y médica. Problemas de salud pública.

\section{RESEARCH AND CURE: KNOWLEDGE AND PROPHYLAXIS OF ENDEMIC GOITER IN ARGENTINA (1916-1958)}

\begin{abstract}
The present paper focuses on the reconstruction of the historical circumstances of knowledge production as well as and the debates about endemic goiter disease during the period 1916-1955 in Argentina. Taking into account the social, political and material dimensions, this text explores the re-signification of scientific and medical knowledge oriented to the prevention and health treatment, through the positioning of several social actors engaged all along the period, and the diverse historical and institutional contexts.
\end{abstract}

KEY WORDS: Endemic goiter. Scientific and medical research . Public health problems. 


\section{INTRODUCCIÓN*}

El presente trabajo se orienta a reconstruir el recorrido histórico de la producción de conocimiento y los debates acerca de la enfermedad del bocio endémico ${ }^{1}$ fundamentalmente entre 1916 y 1955, es decir, entre las primeras investigaciones científicas llevadas a cabo en el Instituto Bacteriológico inaugurado en 1916 bajo dependencia del Departamento Nacional de Higiene y sobre la base de un laboratorio preexistente - y la instrumentación de las primeras medidas de profilaxis, luego del surgimiento de la primera institución especializada en la enfermedad: el Instituto del Bocio de la Universidad Nacional de Cuyo, creado en 1951.

Como veremos, entre los estudios acerca de la etiología y formas de tratamiento de la enfermedad y el establecimiento de medidas de profilaxis efectivas transcurrieron aproximadamente cuarenta años. Sin embargo, no puede pensarse este desplazamiento en la resolución del problema como resultado de los altos costos de investigación y tratamiento, o como consecuencia de los escasos conocimientos acumulados por la ciencia básica: desde principios de la década del 50, los expertos en bocio endémico vinculados a la Organización Mundial de la Salud (OMS) afirmaban que la enfermedad era una de las más fáciles de prevenir, puesto que «la profilaxis no requiere, como la mayor parte de las campañas sanitarias, fuertes erogaciones en obras de ingeniería, hospitales o clínicas, ni precisa tampoco de instrumental o drogas costosas, tampoco necesita personal numeroso o muy especializado» ${ }^{2}$.

Las razones se encuentran en otras dimensiones: intentaremos dar cuenta de los aspectos sociales, materiales y políticos que atravesaron la relación entre producción de conocimiento y su utilización, tomando en cuenta la posición adoptada por diversos actores sociales implicados (políticos, científicos y médicos) y los contextos institucionales e históricos en los que se desenvolvieron. Asimismo, se hará particular hincapié en el papel que desempeñaron médicos y científicos extranjeros en la introducción de las nuevas técnicas de medicina nuclear como método de diagnóstico, en un contexto local favorable

* Agradecemos a Pablo Kreimer sus correcciones y sugerencias, y a María Jesús Santesmases y Diego Hurtado la lectura de las versiones preliminares de este artículo.

1 El bocio endémico es una hipertrofia de la glándula tiroidea que produce abultamiento de la región anterior del cuello y se presenta en ciertas regiones, especialmente en zonas montañosas, en las que son escasas las fuentes geológicas de yodo. Los efectos de la enfermedad pueden dar lugar a retardo mental, sordomudez, enanismo e hipertiroidismo.

2 Stacpoole, H.H. (1954), La profilaxis del bocio endémico en México, Boletín de la Organización Sanitaria Panamericana, p. 288. 
al desarrollo de la física nuclear. Por último, pondremos de relieve la intersección entre dimensiones regionales, nacionales e internacionales, por un lado, y sociales y cognitivas, por el otro, que influyeron en el abordaje de la enfermedad del bocio endémico.

INSTITUCIONES SANITARIAS E INVESTIGACIÓN CIENTÍFICA: LOS PRIMEROS PASOS EN EL ESTUDIO DEL BOCIO

Si bien el tratamiento del bocio con algas marinas es de larga data y ha sido utilizado por diversas culturas, el descubrimiento del yodo por Bernard Courtois y Joseph Louis Gay-Lussac en 1811 fue crucial en los primeros intentos de tratamiento de la enfermedad. Poco después de ese descubrimiento, el médico suizo Jean François Coindet argumentó que era el yodo lo que daba a las cenizas de algas y moluscos sus propiedades benéficas para combatir el bocio y, en 1820, presentó a la Sociedad Suiza de Ciencias Naturales los primeros resultados del empleo de yodo en el tratamiento del bocio ${ }^{3}$. No obstante, debido a la escasez de conocimientos, la aplicación indiferenciada de ese método produjo casos de hipertiroidismo y aumento del tamaño del bocio por dosis excesivas de yodo. El descrédito del tratamiento y profilaxis a través de ese método sólo comenzó a revertirse en 1895, cuando Eugen Baumann descubrió que el yodo era el constituyente normal de la glándula tiroidea.

A principios del siglo XX, el creciente interés en el estudio de las glándulas endócrinas en Estados Unidos impulsaría un proceso de institucionalización de la disciplina, cuyo primer paso fue la creación de la Association for the Study of Internal Secretions (luego Endocrine Society) en 1916, que un año más tarde empezaría a publicar Endocrinology (primera revista especializada en el tema a nivel mundial). Fue en ese contexto que David Marine y sus colaboradores iniciaron una serie de investigaciones en Estados Unidos, que culminarían en un experimento a gran escala destinado a la prevención del bocio endémico entre escolares de Akron, (Ohio), cuyos resultados mostraron el efecto preventivo de un suplemento de yoduro de sodio ${ }^{4}$. Paradójicamente,

3 Coindet (1820), citado por CARPEnTER, K. (2005), David Marine and the Problem of Goiter, Journal of Nutrition, 135 (4), p. 675.

4 Matovinovic, J. y Ramalisgaswami, V. (1959), Tratamiento y Profilaxis del Bocio Endémico, Boletín de la Oficina Sanitaria Panamericana, Marzo, p. 257. La prevención del bocio en ese país se basó en las investigaciones de David Marine y colaboradores. Marine estudió la estructura anatómica de la glándula tiroides, la naturaleza de la hiperplasia glandu- 
siendo aún muy fragmentario el conocimiento sobre el origen de la enfermedad, comenzaron a instituirse métodos probados de profilaxis.

En el plano local, si bien a lo largo del siglo XIX algunos viajeros extranjeros dejaron asentadas sus observaciones sobre el impacto de la enfermedad en determinadas poblaciones 5 , el interés y la preocupación por la endemia cobró vigor en la segunda mitad del siglo XIX, particularmente luego de las cifras de bociosos arrojadas por el Censo Nacional de 1869, por lo que médicos de diversas provincias cordilleranas llamaron la atención acerca de la contundente propagación de la enfermedad, conectándola con aspectos sociales como la pobreza, la alimentación deficiente y las pobres condiciones de higiene, además de la mala calidad del agua ${ }^{6}$. A comienzos del siglo XX, el problema fue motivo de mayor atención por parte de las reparticiones oficiales y la prensa, aunque las autoridades no establecieron políticas sanitarias

lar y la relación entre el contenido de yodo y la estructura de la glándula. Encontró estos cambios y relaciones constantes en ovejas, perros, bueyes y cerdos. Concluyó, en esta etapa de sus investigaciones, que la hipertrofia glandular y la hiperplasia (síntomas del bocio) se debían enteramente a la deficiencia de yodo en la glándula tiroidea y, años más tarde, señaló que el bocio simple era la más sencilla de prevenir de las enfermedades hasta ese momento conocidas. Ver; KimBALL, O.P. (1938), Twenty years in the prevention of goiter (1916-1936). En Transactions of the third international Goiter Conference and the American Association for the Study of Goiter, Washington, p. 57.

5 Así, por ejemplo, Peter Schmidtmeyer, un viajero que pasó el verano de 1821 en Mendoza, anotó sus impresiones acerca de la cantidad y dimensión de los bocios en la población femenina y masculina, y realizó una de las primeras clasificaciones de la enfermedad (bocio difuso y bocio nodular) (SCHMIDTMEYER, P. (1824), Travels into Chile over the Andes in the years 1820 and 1821, London, Longman, Hurst, Rees, Orme, Brown \& Green). En 1823, Manuel Moreno relató en un artículo del primer número de los Anales de la Academia de Medicina la introducción del yodo como terapia en el bocio endémico. Véase QuIROGA, M. (1972), Manuel Moreno, Buenos Aires, Eudeba, pp. 99-100. También, el antropólogo y médico italiano Paolo Mantegazza que vivió en Argentina entre 1854 y 1858, tomó nota de las manifestaciones de bocio endémico en las poblaciones de Jujuy y Salta, asignando a la composición del agua de los ríos aledaños un papel importante en la causa de la endemia. Véase MantegazZA, P. (1949), Cartas Médicas sobre la América Meridional, Buenos Aires, Coni.

6 PerinetTi, H. (1969), Bocio endémico en la Argentina hasta fines del siglo XIX, Boletín de la Academia Nacional de Ciencias de Córdoba, XLIX (1-4), pp. 506-508. Dos hechos que indican el creciente interés por el bocio endémico son la incorporación de varias regiones argentinas afectadas por el bocio endémico a la Géographie Medicale de A. BorDIER (1884), publicada en París, y la tesis doctoral de Francisco R. NIÑo presentada en la Facultad de Ciencias Médicas de la Universidad de Buenos Aires (1892) bajo el título Geografía Médica del Bocio en la República Argentina. Ver PerinetTi (1969), pp. 508-509. 
concretas para combatir la enfermedad, o bien, para investigar sistemáticamente su origen y profilaxis.

Entre fines del siglo XIX y principios del XX comenzó a crearse un contexto institucional favorable para dar los primeros pasos: en 1893 se creó la Oficina Sanitaria Argentina, que fue el punto inicial de un despliegue institucional enraizado en el Departamento Nacional de Higiene (DNH). Así, el estado asumía la agenda de la salud pública a la par de la conformación de todo el aparato administrativo en base a una modalidad de intervención centralizada?.

Las diversas secciones de la Oficina Sanitaria Argentina (Química, Bacteriología y Demografía) tenían la función de asesorar al DNH sobre enfermedades humanas como el paludismo, la lepra, la fiebre tifoidea, la difteria, la rabia, la influenza, la viruela, la peste, el cólera y la tuberculosis. Indudablemente, la preocupación central de las autoridades estaba ligada a las epidemias que ponían en peligro la estabilidad del comercio exterior (pieza clave del modelo agroexportador) y a la regulación del proceso de trabajo, en un momento en que las ciudades se encontraban desbordadas por los nuevos pobladores y por el ingreso de enfermedades contagiosas.

Con el objetivo de dar respuestas a las dificultades sanitarias, comenzaron a crearse en la Oficina Sanitaria una serie de laboratorios y secciones especializadas de institutos, que tenían por función no sólo la investigación, sino también la producción de sueros y vacunas, la construcción de estadísticas bio-demográficas, las tareas de diagnóstico y control sanitario, etc. ${ }^{8}$ En 1916, el antiguo Laboratorio Bacteriológico del Departamento Nacional de Higiene, transformado ya en Instituto fue puesto bajo la dirección del bacteriólogo Rudolf Kraus, contratado en 1913 para elaborar el programa de la nueva institución ${ }^{9}$. El Instituto contaba con las secciones de parasitología y protozoología (a cargo de Arturo Neiva) ${ }^{10}$, patología y organoterapia (Bernardo Houssay),

7 EstéBAnez, M.E. (1996), La creación del Instituto Bacteriológico del Departamento Nacional de Higiene: salud pública, investigación científica y la conformación de una tradición en el campo biomédico. En Albornoz, Kreimer y Glavich (eds.), Ciencia y Sociedad en América Latina, UNQ, Buenos Aires, pp. 429-430 y 432-434.

8 ESTÉBANEZ (1996), p. 433.

9 Sobre Kraus consultar AQuino, L. (1921), El Profesor Doctor Rodolfo Kraus, Revista del Círculo Médico Argentino y Centro de Estudiantes de Medicina, año XXI, n. ${ }^{\circ}$ 235-236, pp. 157-169 y Buch, A. (2006), Forma y función de un sujeto moderno. Bernardo Houssay y la fisiología argentina (1900-1943), Universidad Nacional de Quilmes, Bernal, pp. 111-119.

10 Bacteriólogo y parasitólogo brasileño formado en el Instituto Osvaldo Cruz de Brasil con estudios de posgrado en Estados Unidos. 
sueros y vacunas (Alfredo Sordelli) ${ }^{11}$, estudios experimentales del cáncer (Ángel Roffo) ${ }^{12}$ y terapia experimental (Kraus). Es en este contexto institucional que se llevaron a cabo las primeras investigaciones sobre el bocio.

En 1919, el fisiólogo Houssay realizó una serie de investigaciones experimentales con ratas blancas, en las que consiguió producir bocio experimental a partir de aguas extraídas de territorio salteño, con lo que dejó asentada la necesidad de realizar investigaciones semejantes en gran escala, y sostuvo la hipótesis de que el agua constituía uno de los vehículos del bocio ${ }^{13}$. El impulso para dichas investigaciones parece haber partido de algunas observaciones realizadas por Kraus para verificar la potencial conexión entre la enfermedad de Chagas y el bocio endémico sugerida por investigadores brasileños, y parcialmente descartada en esa ocasión por los investigadores argentinos ${ }^{14}$.

Poco tiempo después, a mediados de la década de 1920, León Goldemberg - médico argentino ligado a la Sociedad de Medicina Interna de Buenos Aires-, proponía la hipótesis de que el bocio observado en algunas áreas no se debía a una deficiencia de yodo, sino a un exceso de fluoruro ingerido a través de alimentos, agua o aire ${ }^{15}$.

Aún años más tarde, la falta de precisión en la identificación de las causas de la enfermedad puede constatarse en la Segunda Conferencia Internacional sobre Bocio Endémico (1932), donde se puso de manifiesto la dificultad para hacer frente a las diferencias en la terminología, la patología y los métodos de investigación entre diversos países y se intentó partir de tres preguntas bási-

11 Químico egresado de la UBA que durante 1912 se había entrenado con los profesores W. Nernst y Emil Fisher en Berlín. Por esos años, se fue especializando progresivamente en química biológica. Profesor de Química Biológica en las facultades de Veterinaria (1915), Ciencias Médicas (1921) y Química (1922). Jefe de la sección Química del Instituto de Fisiología de Houssay hasta 1924.

12 Secretario de la comisión de superintendentes encargada en 1922 de la organización y puesta en marcha del Instituto de Medicina Experimental de la Facultad de Ciencias Médicas de la UBA.

13 Ver Houssay, B.A. (1920a), Bocio producido experimentalmente con agua de Cerrillos (Salta), Revista de la Asociación Médica Argentina, 32, p. 11, y HoussAY, B.A (1920b), Bocio producido experimentalmente por aguas de la provincia de Salta, La Prensa Médica Argentina, 7, p. 31.

14 KRAUS, R. (1919), El problema de la etiología y patogenia del bocio endémico y del cretinismo, Buenos Aires (folleto); (1919), Revista del Instituto Bacteriológico, Buenos Aires, Journal of the American Medical Association, 74 (17), pp. 1198-1199.

15 SCHULD, A (2005), Is dental fluorosis caused by thyroid hormone disturbances? Fluoride, 28 (2), pp. 91-94. Véase también GoldEMBERG, L. (1926), Action physiologique des fluorures, Compt. Rend. Soc. Physiol., 95, pp. 1169-72. 
cas: «¿qué es el bocio endémico? — ¿cómo se origina?— ¿cuáles son los medios para su prevención?» ${ }^{16}$. En algunos trabajos se puso en duda la deficiencia de yodo como causal de la enfermedad, y en otros, incluso se propusieron otros factores causales, como microorganismos o algún «gas o sustancia coloidal» presentes en el agua.

Efectivamente, en la Argentina, los estudios eran aún escasos, las hipótesis endebles y las primeras investigaciones realizadas por Kraus y por Houssay eran más bien un derivado de la preocupación por enfermedades infectocontagiosas, entre las que la endemia del bocio parecía no encuadrarse. Estas investigaciones fueron realizadas por algunos de los colaboradores y discípulos de Houssay, quien en 1920 estaba a cargo del Instituto de Fisiología de la Universidad de Buenos Aires (UBA), desde donde desarrollaría una estrategia de alianzas institucionales y una agenda de investigación en el campo de la fisiología ${ }^{17}$.

En 1924, el nombramiento de Alfredo Sordelli (jefe de la sección Química del Instituto de Fisiología) al frente del Instituto Bacteriológico del DNH, galvanizó en Buenos Aires la existencia de dos polos de labor complementarios y coordinados entre sí ${ }^{18}$. Ese año, frente al auditorio del Instituto Popular de Conferencias del periódico La Prensa, Sordelli instaló el problema del bocio dentro del ámbito de las deficiencias alimenticias, señalando la necesidad de crear un instituto de la nutrición, dada la severidad que revestían en las provincias del norte argentino el bocio y el cretinismo endémico ${ }^{19}$. Sordelli avizoraba que los adelantos de la ciencia de la nutrición a partir de los trabajos de Hopkins, McCollum, Davis, Osborne y Mendel entre 1912 y 1915 iban camino a equipararse al descubrimiento pasteuriano de los gérmenes como causa de enfermedad ${ }^{20}$.

16 Fitzgerald, R.R. (1932), A review of the Internacional Conference on endemic goitre held at Berne, Switzerland, The Canadian Medical Association Journal, december, 1932, pp. 653-656.

17 BUCH (2006).

18 BuCH (2006), p. 272.

19 Sordelli, A. (1924), Bases científicas de la nutrición, Anales del Instituto Popular de Conferencias, X, pp.145 y 147.

20 Sordelli afirmaba que «[...] el conocimiento de las vitaminas y sus funciones ha dado un nuevo impulso a la ciencia de la nutrición, ha reavivado el interés por algunos problemas que se creían resueltos, y ha abierto nuevos rumbos a la fisiología y a la patología. Esta se hallaba últimamente dominada por los maravillosos descubrimientos de Pasteur que provocaron $[. .$.$] una tendencia a explicar todos los procesos mórbidos como obra de agentes nocivos,$ 
En 1924, el DNH impulsó la realización de los primeros estudios sobre bocio endémico, a cargo de doctor Juan T. Lewis (discípulo de Houssay), quien llevó a cabo - de acuerdo a la técnica preconizada en esos tiempos por los norteamericanos David Marine y su asistente O. P. Kimball- una serie de trabajos estadísticos en las provincias del norte, que arrojaron las primeras cifras confiables de población afectada por la enfermedad ${ }^{21}$. En los años siguientes - aunque de manera desarticulada y poco sistemática - se realizarían estudios tendientes a establecer los niveles de prevalencia y los factores coadyuvantes de la endemia.

En 1929, como complemento de los trabajos de Lewis, el químico Pedro Mazzocco $^{22}$ (también colaborador de Houssay) estudió el contenido de yodo en la tiroides, el agua, la tierra y los principales alimentos de la provincia de Salta, y realizó algunos estudios similares en la región del Litoral ${ }^{23}$. Ese mismo año, Salvador Mazza, médico argentino especializado en bacteriología, fue nombrado director de la Misión de Estudios de Patología Regional Argentina (MEPRA) en Jujuy con el objetivo de determinar la extensión y las características de la enfermedad de Chagas en la Argentina. Sus investigaciones realizadas en zonas donde, a pesar de la permanencia del parásito, no se observaba el bocio, terminaron de confirmar la inexistencia de una asociación entre la infección con Trypanosoma Cruzi y los síntomas de hipertiroidismo propuestos por Chagas ${ }^{24}$. Tres años después Mazza y Mazzocco hicieron mediciones comparadas de yodo en hombres y perros bociosos de Jujuy y con

olvidando que la privación de elementos indispensables podía ser la causa de la misma importancia [...]» (SORDELLI (1924), p. 147).

21 Los resultados de sus trabajos pueden verse en LEWIS, J.T. (1924), Características del bocio endémico en las provincias del norte, La Semana Médica, 2, pp. 713-718.

22 El doctor Mazzocco trabajaba junto a Houssay en el Instituto de Fisiología de la UBA. Los resultados de sus trabajos fueron presentados en la Quinta Reunión de la Sociedad Argentina de Patología Regional del Norte. Consúltese MAZzocco, P. (1929a), Investigaciones sobre el bocio endémico y su profilaxis, Revista de la Sociedad Argentina de Biología, 5, pp. 440-497. Ver también Mazzocco, P. (1929), Investigaciones sobre el bocio endémico y su profilaxis, La Semana Médica, 37, p. 356 y Mazzocco, P. y Arias ArandA, C. (1930), Contenido de yodo de la tiroides de ovinos en Salta y Litoral, La Semana Médica, 37, p. 364 y 366.

23 Secco, F.E. (1937), Bocio endémico, Boletín Sanitario del Departamento Nacional de Higiene, 2, p. 160; Houssay, B.A. (1939), La lucha contra la endemia bocio-cretínica, Revista de la Asociación Médica Argentina, XIII (421-422), p. 788.

24 Kreimer, P. y ZabalA, J.P. (2007), Social Problems, Scientific Problems: the reciprocal construction. Chagas Disease in Argentina, Science, Technology and Society, 1 (11); ZABALA, J.P. (2007), Producción y uso de conocimientos científicos vinculados a la enfermedad de Chagas. Argentina, 1915-2000, Tesis doctoral, FLACSO Argentina. 
poblaciones en condiciones normales de la capital jujeña y la ciudad de Buenos Aires ${ }^{25}$. También, en 1937, Sordelli publicó en el Boletín Sanitario del $D N H$ el resultado de una inspección sanitaria efectuada en escolares de los territorios de Misiones y Formosa y en algunas localidades de la provincia de Corrientes $^{26}$. Por último, a mediados de la década del 30 se iniciaron estudios en la provincia de Mendoza para determinar el contenido de yodo de sus aguas y el porcentaje de la población afectada ${ }^{27}$.

Para esa época, los trabajos realizados en diversas regiones permitieron la confección de un informe presentado al DNH $-\mathrm{y}$ publicado en el correspondiente boletín - en el que se esbozaba un mapa de las zonas afectadas del país ${ }^{28}$. Por otra parte, una vez definido (relativamente) el panorama de la endemia, la difusión de su impacto en Argentina alcanzaría el ámbito internacional con la publicación, entre 1938 y 1941, de cuatro informes referidos al tema en la sección «Foreign Letters» del Journal of the American Medical Association ${ }^{29}$.

\section{LA ENFERMEDAD COMO PROBLEMA SOCIAL: CIENTÍFICOS, MÉDICOS Y POLÍTICOS EN LOS INTENTOS DE INSTITUCIONALIZACIÓN}

A partir de mediados de los años 30, los organismos internacionales y algunas instituciones filantrópicas como la Oficina Sanitaria Panamericana

25 Mazza, S. y Mazzocco, P. (1931), Yodemia comparada de hombres y perros bociosos de Jujuy con normales de esta ciudad y de Buenos Aires, Séptima Reunión de la Sociedad Argentina de Patología Regional del Norte, Tucumán.

26 SORDELLI, E.M. (1937), Resultados de una inspección sanitaria efectuada en escolares en los territorios de Misiones y Formosa y en algunas localidades de la provincia de Corrientes, Boletín Sanitario del Departamento Nacional de Higiene, 1, pp. 810-822.

27 TRELLES, R.A. (1937), Las aguas con un contenido elevado de calcio y magnesio favorecen en Mendoza el desarrollo del bocio endémico, Revista de Obras Sanitarias de la Nación, 1 (1); y PERINETTI, H. y Freneau, J.E. (1941), El bocio en las escuelas provinciales y su profilaxis. Presentado a las Jornadas Médicas, Mendoza, respectivamente. Como complemento de las encuestas escolares, la cátedra de química general e inorgánica de la Universidad Nacional de Cuyo, realizó un estudio sobre el contenido de yodo de las aguas de riego y bebida en Mendoza, comprobándose la pobreza en este elemento y demostrando científicamente cuál era la causa de la endemia en la región. Véase Petezze De MARSANO, M.L. (1950), Determinaciones del yodo en el agua de Mendoza, Universidad Nacional de Cuyo, Cátedra de Química General e Inorgánica.

28 Alonso MujicA, J.C. (1939), Geografía Médica, Boletín Sanitario del Departamento Nacional de Higiene, 3, pp. 63-88.

29 Oficina Educacional del Yodo. Corporación de ventas de salitre y yodo de Chile (1950), El bocio en la América latina, Santiago de Chile, Stanley, p. 33. 
(OSP) y la Rockefeller Foundation (RF), comenzaron a conceder un espacio significativo a los problemas de alimentación entre sus políticas sanitarias para América Latina, generando nuevos espacios para su tratamiento ${ }^{30}$. En abril de 1936, la III Conferencia Panamericana de Directores de Sanidad recomendaba a aquellos países que aún no lo hubiesen concretado, la creación de instituciones que realizaran actividades referidas a la alimentación y a la nutrición de la población con fines sanitarios ${ }^{31}$. En 1937, luego de la modificación del plan de estudios de la carrera de medicina de la UBA, se creó la Cátedra de Patología y Clínica de la Nutrición, que fue ofrecida por el decano José Arce al doctor Pedro Escudero ${ }^{32}$. Un año más tarde, el presidente Agustín P. Justo, fundó el Instituto Nacional de Nutrición ${ }^{33}$, dando así rango nacional al ex-Instituto Municipal de Enfermedades de la Nutrición (Hospital Rawson), creado por la Asistencia Pública en 1928 bajo la dirección del mismo Pedro Escudero ${ }^{34}$.

Desde el Instituto Nacional de Nutrición comenzaron a surgir propuestas para la creación de una institución de carácter público destinada al estudio, tratamiento y profilaxis de la enfermedad en Mendoza, una de las principales provincias afectada por la endemia. A fines de 1939, el diario Los Andes anunciaba que, en una visita a la provincia de Mendoza realiza-

30 Sobre la RF en relación a los problemas de nutrición, véase DARBY, W.J. (1991), The Food and Nutrition Board: a personal retrospective, Nutrition Today, julio-agosto, 1991, disponible en http://findarticles.com/p/articles/mi m08441/is n4 v26/ai 11243063 (consultado el 21-09-06). Sobre la OPS véase CuETO, M. (2004), El valor de la salud. Historia de la Organización Panamericana de la Salud, OPS, Washington.

31 Departamento Nacional de Higiene (1937), III Conferencia Panamericana de Directores de Salud. En, Boletín Sanitario del Departamento Nacional de Higiene, 7, p. 9.

32 Interesado en los problemas de nutrición detectados en los soldados reclutados en la primera guerra, Escudero inició en 1921 una campaña a favor del estudio de la nutrición en nuestro país a través del estratégico lugar de la tercera cátedra de Clínica Médica de la UBA, las publicaciones médicas y científicas, la radio y la prensa escrita. Sobre Escudero, ver BARrios Medina, A. (1993), Historia de la contribución de Bernardo Houssay al conocimiento de la fisiología de la hipófisis, Tesis de doctorado, Facultad de Farmacia y Bioquímica, Universidad de Buenos Aires.

33 Decreto 125.808. Para la organización del Instituto Nacional de Nutrición, ver LANDABURE, P.B. (1944), Revista Argentino-Norteamericana de Ciencias Médicas, pp. 913-919.

34 Asimismo, Argentina comenzó a tener una participación destacada en las reuniones internacionales destinadas a discutir diversos problemas vinculados a la nutrición. En 1939 se llevó a cabo en Buenos Aires la Tercera Conferencia Internacional de Alimentación, con el auspicio de la Sociedad de Naciones y bajo la presidencia de Pedro Escudero. Véase ESCUDERO, P. (1940), Boletín de la Oficina Sanitaria Panamericana, pp. 330-336. 
da por Escudero y su colaborador, Enrique Pierángeli, el primero recomendó la creación de un Instituto del Bocio ${ }^{35}$. La recomendación de Escudero confluyó con —o tal vez incluso impulsó - la iniciativa de algunos políticos, que iniciaron una campaña a favor de su tratamiento e investigación de la misma. Uno de ellos fue el senador por Salta y presidente de la Comisión de Higiene y Asistencia Social del Senado, Carlos Serrey quien, ya en 1934, había gestionado la concesión de un subsidio para dar rango nacional al Instituto Municipal de la Nutrición. El otro fue el senador socialista Alfredo L. Palacios - también miembro de la Comisión de Higiene y Asistencia Social - quien, desde su tesis doctoral en Medicina, La Fatiga (1918), había denunciado el efecto nocivo que las desigualdades sociales y económicas habían tenido sobre la salud física y moral de las clases populares en las provincias del Noroeste argentino. A fines de la década del 30, luego de una gira por Santiago del Estero, Catamarca, Tucumán, Salta, Jujuy y La Rioja, Palacios llamaba la atención sobre los estragos del paludismo y el bocio endémico en las zonas de Los Cerrillos y San Lorenzo de la provincia de $\mathrm{Salta}^{36}$. Un año más tarde, coincidentemente con la recomendación de Escudero, Palacios participó en la elaboración de un proyecto para la creación de un Instituto del Bocio en Mendoza ${ }^{37}$.

El 29 de agosto de 1939 Palacios y Serrey invitaron a Houssay a disertar acerca del proyecto de creación del Instituto de Bocio ${ }^{38}$. La motivación de los senadores a participar de este emprendimiento quedará expresada en el libro de Palacios titulado Pueblos desamparados ${ }^{39}$, en el que la enfermedad del bocio endémico se enlaza con un conjunto de problemas sociales, entre ellos, los problemas de nutrición. Allí, el senador se haría eco de la necesidad de

35 Los Andes, 6 de noviembre de 2005, http://losandes.com.ar/2005/1106/efemerides.htm (consultado el 28/8/06).

36 Palacios, A.L. (1938), El dolor argentino, Buenos Aires, Claridad.

37 En este punto debe tomarse en cuenta que Escudero mantuvo una relación fluida al menos con ciertos legisladores socialistas y consiguió canalizar algunas iniciativas por medio de legisladores de esa extracción. Por otra parte, Palacios y Escudero habían compartido en el pasado sitiales en el Consejo Directivo de la Facultad de Ciencias Médicas (UBA).

38 Sobre este encuentro véase CAro FigueroA, G. (1997), Houssay, Alfredo Palacios, y el Senador Carlos Serrey en torno al Bocio endémico, Todo es Historia, pp. 90-92. Sobre la posición pública de Houssay en torno a los fundamentos científicos de la lucha contra la endemia bocio-cretínica, véase HousSAY (1939).

39 Palacios, A.L. (1942), Pueblos desamparados, Buenos Aires, Kraft. El libro reúne sus discursos parlamentarios de 1941 y una síntesis de la información resultante de la visita al noroeste argentino que Palacios (acompañado por el senador Villanueva) transmitió a sus colegas. 
instalar el tema en instituciones públicas de investigación, afirmando que la etiología del bocio permanecía desconocida, por lo cual era urgente la intervención de los poderes públicos para investigarla y la creación de un instituto de investigación, tratamiento y profilaxis del bocio con asiento en Mendoza. Si bien se mostraba informado de las hipótesis más extendidas sobre las causas de la endemia, señalaba que la etiología del bocio obedecía a "causas específicas que deben ser estudiadas científicamente», pero además a problemas sociales como «la mala alimentación, a la falta de higiene personal y social, a la miseria, en una palabra». Del mismo modo, en la reunión con los senadores, Houssay había señalado no las causas sino las consecuencias sociales de la endemia, haciendo alusión a uno de los tópicos centrales de la higiene social de los años 30: la preservación del capital humano ${ }^{40}$.

El relativo consenso acerca de la necesidad de encarar el bocio endémico como problema de investigación y como problema social no aparece tan nítidamente al momento de definir el enclave geográfico-administrativo y el modelo organizativo del futuro instituto. En primer lugar, desde mediados de la década del 20, los esfuerzos de Houssay por consolidar el modelo experimental y fisiológico para la medicina, distinguiéndola de la clínica, lo llevarían a privilegiar modelos institucionales basados en las ciencias fundamentales, en contraposición los modelos organizativos basados en el estudio de enfermedades específicas ${ }^{41}$. Basado en esta concepción, Houssay enfatizó, durante la reunión con los senadores, la necesidad de que confluyeran en el estudio del bocio especialistas representativos de las diversas disciplinas: endocrinología, metabolismo, anátomo-patología, química, veterinaria, geología e hidrología ${ }^{42}$.

En segundo lugar, la propuesta de crear un instituto de alcance provincial (en Mendoza), se encontraba muy a tono con una serie de debates que se lle-

40 Belmartino, S. et al (1987), Las instituciones de salud en la Argentina: desarrollo y crisis, SECyT, Buenos Aires, p. 100. En este sentido, Belmartino (p. 107) señala que en un proyecto de reorganización de los servicios sanitarios de 1936, se ponía énfasis en enfermedades que hasta entonces habían recibido menos atención: «Esta higiene social comprende hoy, no ya tan sólo las enfermedades infecto-contagiosas o transmisibles, sino también otras de distinto tipo (...) (que) constituyen un motivo de invalidez para el individuo y para la sociedad». Respecto del bocio endémico, aún en 1954, en un boletín de la Organización Sanitaria Panamericana, se afirmaba que «la incidencia de la debilidad mental, distinta del cretinismo, aumenta en forma marcada en las zonas de bocio endémico. Véase GRUPO DE ESTUDIOS DE LA OMS SOBRE EL BOCIO ENDÉMICO (1954), Informe Final, Boletín de la Organización Sanitaria Panamericana, p. 299.

41 BuCH (2006), pp. 260-262.

42 CARo Figueroa (1997), pp. 91-92. 
varon a cabo durante la década del 30 sobre la necesidad o no de descentralizar las funciones del DNH. Dentro de la bancada socialista, al igual que entre algunos diputados del interior que defendían la autonomía provincial, había cobrado particular fuerza la apelación antiburocrática y descentralizadora. Incluso, en algunos casos, la autonomía y la especialización eran defendidas en función del problema involucrado, afirmando que, estando la zona afectada a muchas leguas de Buenos Aires, no había motivo para mantener «ese cordón umbilical eterno de centralización burocrática» ${ }^{43}$. En contraposición a esta argumentación, Houssay negaba la posibilidad de encarar una profilaxis desde visiones fragmentarias de la enfermedad o desde parcelas administrativas desconectadas entre sí. Para él la lucha contra el bocio requería de una política a escala nacional, que resolviera las carencias alimenticias y los problemas de suministro de agua potable y sal yodada a las poblaciones afectadas ${ }^{44}$.

El modelo institucional descentralizado para el abordaje de enfermedades endémicas en distintas regiones se había puesto en práctica con la creación de la MEPRA instalada en la provincia de Jujuy en 1929. La MEPRA fue creada por Mazza paralelamente a la fundación de la Sociedad de Patología Regional del Norte (SPRN) que, a lo largo de la década del 30, creó filiales en diversas provincias. En ese marco, Mazza obtuvo la colaboración de una red de médicos - en su mayoría con escasa o nula tradición en investigación científicaentre los que difundió distintas patologías de la región ${ }^{45}$. Fue en una de las reuniones periódicas organizadas por la SPRN, que el químico Mazzocco presentaría los resultados de sus estudios sobre bocio llevados a cabo en Salta. Tres años más tarde (en 1931) Mazzocco y Mazza realizarían estudios conjuntos en hombres y perros con bocio de la provincia de Jujuy ${ }^{46}$.

El dato es relevante porque la novena Reunión de la SPRN (1935) fue llevada a cabo en Mendoza, hecho que posiblemente haya impulsado la creación, en 1938, de la sección andina de la MEPRA. En la reunión de 1935, el médico mendocino Carlos Padín presentó un trabajo referido a las formas clínicas del bocio junto al médico Héctor Perinetti ${ }^{47}$. Ambos médicos tendrían un importante rol como impulsores del proyecto de creación de un Instituto del Bocio con asiento en Mendoza.

43 Belmartino (1987), p. 100.

44 Caro Figueroa (1997), p. 92.

45 ZABALA (2007), pp. 98-99.

46 MAZZA y MAZZOCCO (1931).

47 Padín, C. y PerinetTi, H. (1935), Formas clínicas del bocio en Mendoza, novena Reunión de la Sociedad Argentina de Patología Regional, Mendoza, 2, pp. 672-676. 
En 1941, el gobernador de Mendoza, Adolfo Vicchi envió a la Legislatura un proyecto para la creación del Instituto del Bocio y designó una comisión honoraria presidida por Enrique del Castillo e integrada por los Luis Carrer, Carlos Segura Walrond, José Freneau, Carlos Padín, Héctor Perinetti ${ }^{48}$ y Ernesto Maneschi. Previamente, Obras Sanitarias de la Nación había realizado estudios del contenido de yodo en el agua de Mendoza y, en 1940, el Cuerpo Médico Escolar efectuó, bajo la dirección de Perinetti y Freneau, una encuesta en la que examinó a la casi totalidad de los escolares de la provincia, demostrando la existencia de un $46 \%$ de la población afectada ${ }^{49}$. El proyecto de Instituto, que recibió el impulso de los senadores Gilberto Suárez Lagos (por la provincia de Mendoza) y Palacios, recién se concretó diez años más tarde ${ }^{50}$.

Sin embargo, en 1942 se creó el Departamento de Nutrición de Mendoza, dentro del cual se crearía, años más tarde, la «División Bocio» ${ }^{51}$. La institución formaba parte del proyecto llevado a cabo por Escudero desde el Instituto Nacional de Nutrición, cuya versión original había contemplado el establecimiento de filiales provinciales, reclamadas sin éxito por Escudero ${ }^{52}$. La alternativa que ensayó el instituto fue el auspicio de departamentos de nutrición dependientes de las secretarias provinciales de sanidad, que estuvieron dirigidos por médicos y dietistas formados por el Instituto Nacional de Nutrición. El primero en crearse fue el de Mendoza.

48 Durante su estadía en Buenos Aires (donde estudió medicina), había trabado amistad con el endocrinólogo mendocino Enrique B. del Castillo, (entonces a cargo del consultorio del bocio del Hospital de Clínicas), que le recomendó estudiar el problema en Mendoza. En 1932 Perinetti regresó a Mendoza y se desempeñó como médico agregado de la Dirección General de Salubridad de la provincia.

49 PerinetTi, H.A. (1990), Bocio endémico en Mendoza y el Instituto del Bocio, Boletín de la Academia Nacional de Medicina de Buenos Aires, 68, $2^{\circ}$ semestre, p. 527; Trelles (1937); PERINETTI y FRENEAU (1941).

50 PerinetTi, H.A. (2007), Breve historia del bocio en América Latina y del Instituto del Bocio en Mendoza, Revista Médica Universitaria, Facultad de Ciencias Médicas-Universidad Nacional de Cuyo, 3 (1).

51 La iniciativa fue seguida por las provincias de Santa Fe, Entre Ríos, Buenos Aires, San Luis y Corrientes. Véase Escudero, P. (1945), La obra cultural y económico-social de los médicos dietólogos y dietistas graduados en el Instituto Nacional de la Nutrición (de 1935 a 1944), Revista de la Asociación Argentina de Dietología, 3, pp. 114-116.

52 Escudero, P. (1939), L'Institut National de la Nutrition, La Presse Médicale, II, p. 6; (1941) Instituto Nacional de Nutrición, 1-2. 


\section{CIENCIA, PRODUCCIÓN Y SALUD PÚBLICA: HACIA LA PROFILAXIS}

El debate en torno al tratamiento y profilaxis de la endemia, sostenido durante la Segunda Conferencia Internacional sobre Bocio Endémico (1932) puso en evidencia dos modos de encararla: como «problema social» o como «enfermedad». El eje del debate estuvo en la necesidad o no de que la profilaxis alcanzara a toda la población a través de la obligatoriedad en el uso de sal yodada. La diferencia es importante, puesto que la postura a favor de esta medida suponía considerar a la endemia como un problema social que requería la intervención del estado, mientras que su contraria suponía la existencia de un problema de salud, solucionable en el acotado ámbito de la interacción médico-paciente (prescripción individual de tratamiento con yodo) y en la «higiene personal y social» ${ }^{53}$. El debate pone de relieve el hecho de que las definiciones, las explicaciones causales y las resoluciones que sostienen los especialistas, es decir, los aspectos cognitivos del debate, tienen implicancias en términos de la interpelación (o no) a otros actores, en este caso, el estado y los empresarios productores de sal.

Si bien algunos de los estudios sobre bocio endémico realizados durante las décadas del 20 y del 30 fueron acompañados del establecimiento de medidas profilácticas, éstas resultaban onerosas y tuvieron resultados parciales ${ }^{54}$. La modalidad implementada fue similar a la utilizada en algunas regiones de Estados Unidos y en Suiza, y consistió en el suministro de una pastilla de yodo a todos los escolares ${ }^{55}$. Sin embargo, para el doctor Secco, médico del DNH, este mecanismo suponía dos dificultades: a) a pesar de cubrir una de las franjas de población más vulnerables (los adolescentes), no tenía alcance en las otras dos franjas más expuestas (el feto y las mujeres embarazadas o en período de lactancia); b) al no ser un procedimiento general y automático por el cual el yodo se incorpora junto con la ingesta de agua o alimentos, la efectividad de la profilaxis estaba sujeta a los avatares políticos y económicos o librada a la prevención y tratamiento individual. Afirmaba, además, que las «autoridades competentes en el problema proponen que la profilaxis general se haga a base de sal, o agua, o ciertos alimentos de yodo... [pero] ...en el caso de la yodación del agua de abastos públicos, un método ya probado en Rochester, Nueva York, no había podido comprobarse su inocuidad y eficacia» ${ }^{56}$.

53 FitzGerald (1932), p. 656.

54 Fontana, M.A. (1939), El bocio endémico y su profilaxis en la República Argentina, Best Hermanos, Mendoza. Tesis presentada para optar al título de Doctor en Medicina, Universidad Nacional de La Plata, Facultad de Ciencias Médicas, p. 18.

55 SeCCO (1937), p. 163 y PERINETTi (1990) p. 527.

56 SECCO (1937), pp. 162 y 164. 
En base a cierto consenso internacional en torno al método de profilaxis considerado más adecuado, en 1946, Bernardo Leiva, médico y diputado por la provincia de Mendoza, presentó un proyecto de ley provincial sobre uso de sal yodada, que luego de numerosos debates fue promulgada el 26 de diciembre de 1946. El método había sido ya recomendado en la Conferencia sobre Agricultura y Alimentación de la Naciones Unidas (1943) y comenzaba a legislarse en algunos países de América Latina: Perú en 1940, México en 1942, Brasil en 1944. Sin embargo, la puesta en vigencia de la nueva ley no resolvía automáticamente el problema de la inexistencia de sal yodada en el país, que suponía la adquisición de nuevas técnicas y maquinarias para el procesamiento de la sal, la estandarización de los niveles óptimos de yodo y el establecimiento de mecanismos de comercialización entre las poblaciones afectadas.

Según F.C. Kelly, director de la Oficina Chilena del Yodo de la Corporación del Salitre Anglo-Chilena con asiento en Londres, hasta 1945 sólo tres grupos de investigación en el mundo habían realizado estudios representativos acerca de la estabilidad y fijación del yodo en sal de consumo humano ${ }^{57}$. El artículo de Kelly no mencionaba, sin embargo, las investigaciones realizadas por la Wisconsin Alumni Research Foundation, que lograron obtener y patentar un procedimiento de fijación de la sal yodada. Según se afirma en un editorial del Boletín de la Sociedad Médica de Mendoza, fue ese el procedimiento ofrecido como donación a la Argentina ${ }^{58}$.

57 Kelly, F.C. (1954), Estudios sobre la estabilidad de los compuestos de Yodo en la sal Yodada, Boletín de la Organización Sanitaria Panamericana, p. 304. Los primeros trabajos fueron realizados entre 1923 y 1927 por el grupo del Laboratorio Federal de Salud Pública de Berna. En 1939 y 1940, investigadores de la Universidad de Michigan (EE.UU), publicaron sus resultados en el Journal of Michigan Medical Society. Por último, los científicos del Departamento de Investigaciones Científicas e Industriales de Nueva Zelanda, dieron a conocimiento público sus investigaciones en 1938 y, nuevamente, en 1945.

58 El texto decía: «Obra en poder de la Sociedad Médica de Mendoza copia de las referencias y de la correspondencia oficial mantenida entre el Instituto Nacional de la Nutrición y la Wisconsin Alumni Research Foundation. Esta documentación se refiere a todas las tramitaciones que se realizaron para obtener el procedimiento de fijación de la sal yodada inventada por la Wisconsin Alumni Research Foundation, que dicha institución ofreciera a nuestro país y que divulgada por el Instituto Nacional de la Nutrición en la comunicación hecha a la Asociación Argentina de Dietología, hace que este procedimiento no pueda ser patentado por nadie, puesto que por este simple hecho su conocimiento ha pasado al dominio público. La Sociedad Médica de Mendoza se complace en destacar el acto de la WRF que expresa por sí sólo la generosidad de este gesto de solidaridad humana». Véase EsCUDERO, P. y RoTHMAN, B. (1946), Los fijadores de yodo en la fabricación industrial de sal yodada, Boletín de la Sociedad Médica de Mendo$z a, 25$, pp. 1-17. 
Sin embargo, como se puso de manifiesto en otros países de Latinoamérica, para lograr la erradicación de la enfermedad era necesario, además del manejo de las nuevas técnicas y la provisión del equipamiento para la yodación de la sal, la incorporación del sector productivo. En 1937, México había iniciado una Campaña de Lucha contra el Bocio, dirigida por el doctor Herbert H. Stacpoole, que condujo a promulgar una ley que establecía el uso exclusivo de sal yodada y la composición química que ésta debía tener. Sin embargo, Stacpoole explicaba que, en la época en la que se dictó la norma, durante la Segunda Guerra Mundial, solamente dos empresas tenían evaporadoras para refinar sal y resultaba imposible conseguir maquinaria y equipo, por lo que los fabricantes se mantuvieron indiferentes frente a las indicaciones de la ley, alegando no estar en condiciones económicas de cumplirla ${ }^{59}$. A eso debe agregarse el hecho de que muchos países en desarrollo no utilizaban sal refinada y no existían, hasta entonces, métodos de yodación de sal cruda.

La dificultad para poner en práctica las medidas establecidas en la legislación mendocina sobre la profilaxis del bocio se explica, por lo tanto, por diversas razones. Según señala Perinetti, en julio de 1947, en el afán por perfeccionar su ley, Leiva presentó un nuevo proyecto que no obtuvo despacho, pero que derogó la ley anterior: es decir que parecía ser «peor el remedio que la enfermedad». A ello se agregó la inexistencia de sal yodada en el país ${ }^{60}$.

\section{UNIVERSIDAD, ESTADO E INSTITUCIONES EXTRANJERAS EN LA CREACIÓN DEL INSTITUTO DEL BOCIO}

En 1946, con la llegada a la presidencia de Juan Domingo Perón, se produjo un cambio significativo en el sistema y la política sanitaria. Ese año se creó la Secretaría de Salud Pública (que tres años más tarde adquiría el rango de Ministerio), cuyo manejo sería confiado al médico Ramón Carrillo. Carrillo adscribía a las ideas sanitaristas, cuyos principios se apartaban de la concepción estrictamente técnica que apuntaba a combatir los agentes infecciosos una vez que ingresaban en el organismo, para centrarse en la prevención y en las enfermedades regionales vinculadas a razones geográficas y socioculturales $^{61}$. Así, entre 1946 y 1947, la Secretaría de Salud Pública confeccio-

59 StACPOOLE (1954), pp. 289-293.

60 PerinetTi (1990), pp. 527-528.

61 Kohn LoncaricA, A. y SAnchez, N. (2003), El sanitarismo argentino y su contribución a la Salud Pública: ejemplificado con la obra de Cecilio Romaña (Aproximación a algu- 
nó un informe estadístico de alcance nacional acerca del bocio endémico, que ocupaba un lugar dentro de ese grupo de enfermedades que preocupaban a Carrillo ${ }^{62}$. Del mismo modo, la nueva Secretaría se propuso reforzar la presencia simbólica del Estado en materia de salud, divulgando por diversos medios - charlas, proyección de películas, audiciones radiales y colocación de afiches en diversos ámbitos - pautas sanitarias que, según se creía, incidirían en el bienestar (anatómico y psicológico) de la población y en la riqueza material del país. Entre los afiches confeccionados para esa campaña, llevada a cabo por el Instituto de Educación y Propaganda Sanitaria y la Dirección de Política y Cultura Sanitaria, se incluía al bocio endémico dentro de un grupo de enfermedades sociales, que también abarcaba el alcoholismo, la brucelosis y la sífilis ${ }^{63}$.

En 1951 se creó la «División Bocio» del Instituto de la Nutrición dependiente del Ministerio de Salud Pública de la provincia de Mendoza, integrada por los cirujanos Luis N. Staneloni y Jorge Nacif Nora y dirigido por Héctor Perinetti (Decreto n. ${ }^{\circ}$ 1699/51 del PE de la Provincia). Simultáneamente, Perinetti ocupó la dirección del Instituto del Bocio de la recientemente creada Facultad de Ciencias Médicas «Tomás Perón», que trabajaría con la colaboración de la División Bocio del Hospital Central. De hecho, ambos organismos funcionarían como una unidad dotada de una triple labor: asistencial, de profilaxis y de investigación. El personal del Instituto del Bocio quedó así conformado por L.N. Staneloni, C.N. Colque, M.L. Olascoaga (médico militar) y, en el Laboratorio, el bioquímico militar Juan Eleazar Itoiz y Sara Barbeito.

Previamente a la conformación de ambas instituciones, Perinetti viajó a Estados Unidos para perfeccionarse en la patología tiroidea y estudiar la yodación de la sal, en la Clínica de Tiroides del Massachusetts General Hospital (MGH), establecida en la década del 20 por el Profesor James Howard Means $^{64}$. En 1939, la Universidad de Harvard comenzó la construcción de un

nos ejes temáticos centrales), Médicos y Medicina en la Historia, II (8), p. 9.

62 Secretaría de SAlud Pública (1946-1947), El bocio en la República Argentina, 1939-1945. Estadística preparada por el Gabinete de Investigaciones Técnicas, Archivo de la Secretaría de Salud Pública, 1 (3), pp. 56-59.

63 RAMACCiOTTI, K. (2004), Plasmar la raza fuerte. Relaciones de género en la propaganda sanitaria de la Secretaría de Salud Pública de la Argentina: 1947-1949. En RAmacciotTI, K. y VAlobra, A. (comp.), Generando el peronismo. Estudios de cultura, política y género (1946-1955), Buenos Aires, Proyecto Editorial, 2004, pp. 19-64.

64 Means formó en 1936 un equipo con Robley Evans y Arthur Roberts -físicos del Massachusetts Institute of Technology (MIT) — para realizar estudios con radioyodo (I-128) en tiroides de conejos. Véase MC GEEHEE, H. (1981), James Howard Means and his romance 
ciclotrón que permitiría la producción (entre otros radioisótopos) de radioyodo para los primeros tratamientos de hipertiroidismo e investigaciones llevadas a cabo bajo la responsabilidad del grupo MGH-MIT. Sin embargo, la difusión de dichas técnicas fuera de los Estados Unidos debió esperar a la finalización de la Segunda Guerra Mundial.

Paralelamente, en la Argentina, el endocrinólogo Enrique B. del Castillo creó la Sociedad Argentina de Endocrinología, institucionalizando los intercambios de un grupo de endocrinólogos dedicados a la investigación ${ }^{65}$. Pasada la contienda mundial, la Clínica de Tiroides del MGH atraería a una permanente corriente de visitantes de otros países, entre los que pueden contarse Reforzo Membrives y Carlos Galli Mainini, discípulos y colaboradores de del Castillo en el primer servicio hospitalario de endocrinología, que posiblemente hayan contribuido a difundir las nuevas técnicas en el país ${ }^{66}$. Según Means, debido a la reciente introducción de nuevos métodos de estudio (yodo radioac-

with the thyroid gland, The American Journal of Medicine, (70) 6, pp. 1158-1160. En 1938, G. Seaborg y J.J. Livingood, que trabajaban en el Laboratorio de Radiación de Berkley (donde en 1937 se instalara el primer ciclotrón), descubrieron el I-131, que una tenía mayor duración y permitía las investigaciones en humanos como las que un año más tarde llevaron a cabo J.G. Hamilton y M.H. Soley (también de Berkley). En 1939, Livingood sería contratado por la Universidad de Harvard para la construcción de un ciclotrón. Sobre este tema, véanse ADELSTEIN, S.J. (2001), Robley Evans and what physics can do for medicine, Cancer Biotherapy \& Radiopharmaceuticals, 16 (3), pp. 179-185; SAWIN, C.T. y BECKER, D.V. (1997), Radioyodine and the treatment of hyperthyroidism: the early history, Thyroid, 7 (2), pp. 163-76; Martin, R., Ringo R. y Teng, L. (1987), Physics Today, julio; Hamilton, J.G. y Soley, M.H. (1939), Studies in Yodine Metabolism by the use of a new Radioactive Isotope of Yodine, American Journal of Physiology, 127, pp. 557-572.

65 Enrique del Castillo, fue uno de los fundadores de la Sociedad Argentina de Endocrinología en 1939 y, poco más tarde, crearía el primer servicio de endocrinología clínica del país en el Hospital Rivadavia (Buenos Aires).

66 Ya en 1944 Membrives habría advertido a Houssay acerca de la importancia del uso del yodo radioactivo en el tratamiento clínico de problemas de la tiroides durante su estadía en la Mayo Clinic. Consúltese Barrios Medina, A. (2002), Ciencias Biomédicas. En De MARCO, M.A. (coord.), Nueva Historia de la Nación Argentina, Planeta, Buenos Aires, IX, pp. 504 y 518. En 1947, la Revista Farmacéutica, órgano de la Sociedad Nacional de Farmacia y Bioquímica, reflejaba la importancia de los usos pacíficos de la energía nuclear e instaba a los «profesionales argentinos a la investigación, a la creación de nuevos centros de investigación y a imitar la tarea de los investigadores de otros en el estudio del metabolismo de los organismos biológicos mediante el uso de los radioisótopos». Véase BANFI, R. (1947), Importancia de los isótopos en el estudio de los mecanismos vivos, Revista Farmacéutica, 90 (9), pp. 379-388. 
tivo) y de drogas anti-tiroideas, «la investigación de la fisiología tiroidea, tanto normal como patológica, estaba en pleno apogeo en ese momento» ${ }^{67}$.

Para 1950, cuando arribó Perinetti, la Clínica estaba a cargo de John B. Stanbury, y había incorporado entre sus investigadores a Douglas Riggs, del Departamento de Farmacología, y al físico Gordon Brownell, del MIT. La presentación de casos clínicos que realizó Perinetti ante ese grupo, impulsó la concreción de un proyecto que venía gestándose con anterioridad, según relata Means:

Durante varios años, en la Clínica de Tiroides del Massachussets General Hospital (Boston), expresamos el deseo de efectuar estudios geomédicos de las enfermedades de la glándula tiroides, pero no hicimos nada más que hablar de ello. Hasta que un día, a mediados de 1950, el doctor Perinetti, del Hospital Central de Mendoza, de Argentina, nos honró con su visita ${ }^{68}$.

En esa ocasión, surgió el proyecto de realizar un estudio conjunto en Mendoza, empleando los nuevos métodos de medición de la función tiroidea ${ }^{69}$. A su regreso, Perinetti se hizo cargo del Instituto y de la «División Bocio» y, llegó a Mendoza el grupo de científicos estadounidenses (Douglas Riggs, Gordon Brownell, Eleanor Brown y John Stanbury) con el objetivo de llevar a cabo experiencias sobre fisiología del yodo, tendientes a establecer la cantidad de yodo de los bociosos de la provincia, las cantidades que eran capaces de absorber, utilizar y eliminar de su organismo ${ }^{70}$. Al plantel conformado en el Instituto del Bocio se sumaría un grupo de endocrinólogos en calidad de asesores clínicos: Rodolfo Q. Pasqualini (fundador y director del Instituto Nacional de Endocrinología desde 1948), Reforzo Membrives (subdirector del mismo Instituto) y Enrique B. del Castillo, junto a Raúl Trucco y Alberto Houssay ${ }^{71}$.

67 Stanbury, J.B., Brownel, G.L., Riggs, D.S., Perinetti, H., Itoiz, J. y Del CastiLLO, E.B. (1956), Bocio endémico, El Ateneo, Buenos Aires.

68 STANBURY et al. (1956), p. 9.

69 Stanbury, J.B. (2003), Conferencia en Homenaje a la memoria del Prof. Dr. Héctor Perinetti (primera parte), Revista Argentina de Endocrinología y Metabolismo, 40 (1). En http://www.raem.org.ar/numeros/2003.1/5informe.pdf (consultado el 7/3/09).

70 Los Andes, 21 de junio de 1951, p. 4.

71 Stanbury et al. (1956). Pasqualini fue ayudante de la Cátedra de Fisiología de Houssay entre 1931 y 1943. Fundó y dirigió el Instituto Nacional de Endocrinología durante la gestión de Carrillo, que consideraba a esta institución como una herramienta fundamental de sus políticas de salud pública. Años atrás, había realizado estudios sobre el bocio en la provincia de Misiones. Véase PAsQuAlini, R.Q. y LuXARDO, J.C. (1946), Bocio endémico en la Gobernación de Misiones, Revista de la Asociación Médica Argentina, LX, p. 1010. 
La novedad de los estudios llevados a cabo en cooperación con los estadounidenses consistía, por un lado, en la utilización de isótopos radioactivos (I-131) en el campo de la biomedicina y, por otro, en la realización de una investigación que apuntaba a comprender la fisiopatología de la enfermedad, además de las potenciales complicaciones derivadas de su tratamiento y profilaxis, como la enfermedad de Basedow ${ }^{72}$. Los resultados de estos estudios fueron publicados en inglés (1954) y en español (1956) en un libro que rápidamente se convirtió en referente a nivel internacional y que inspiró estudios similares en América Latina ${ }^{73}$.

En esa experiencia intervinieron factores tanto locales como internacionales. En primer lugar, a fines de la década del 40, el bocio endémico pasó a formar parte de la agenda de los organismos internacionales de salud, impulsando iniciativas por parte de los gobiernos nacionales. Entre 1948 y 1953 se llevaron a cabo las tres primeras Conferencias Latinoamericanas de Nutrición, patrocinadas por la Organización Mundial de la Salud (OMS) y la Organización de las Naciones Unidas para la Agricultura y la Alimentación. En las dos primeras conferencias realizadas en Montevideo (1948) y Río de Janeiro (1950) se reconoció al bocio endémico como un serio problema sanitario en la mayoría de los países latinoamericanos, por lo que el tema fue incluido en el temario de la tercera Conferencia a realizarse en Caracas en $1953^{74}$. En 1949, la OMS había enviado circulares a los gobiernos, requiriendo información acerca de la incidencia del bocio en el país, las medidas tomadas para prevenirlo y las evidencias de su eficacia. En una reunión realizada en 1949 con expertos en nutrición bajo los auspicios de la OMS y la Organización de las Naciones Unidas para la Agricultura y la Alimentación (FAO), se propuso también promover entre los gobiernos el uso de sal yodada

72 Los estudios realizados en Mendoza demostraron que la enfermedad de Basedow podía presentarse si la dosis terapéutica de yodo era considerablemente mayor que la necesidad diaria de ese elemento; MATOVINOVIC y RAMALISGASWAMI (1959).

73 Stanbury, Brownel, Riggs, Perinetti, Itolz y Del Castillo (1956). En 1954, investigadores del Instituto de Investigaciones Médicas de Caracas (Venezuela) señalaban que las investigaciones de Stanbury y col. «han mostrado la importancia de establecer patrones locales de fijación de yodo radioactivo, ya que la captación de esta substancia varía con relación a la disponibilidad de yodo en el agua y la zona en donde viven los sujetos estudiados». Consúltese De VenenzI, F., Roche, M. y Gerardi, A. (1955), Captación de yodo radioactivo (I-131) por sujetos eutiroideos de nuestro medio y algunas consideraciones sobre aplicación al diagnóstico de las enfermedades tiroideas, Acta Médica Venezolana, 3 (4), p. 3.

74 SCRIMSHAw, N.S. (1954), El bocio endémico en la América Latina, Boletín de la Organización Sanitaria Panamericana, p. 277. 
y la realización de estudios sobre la etiología de la enfermedad ${ }^{75}$. Probablemente, esta «internacionalización» de la lucha contra la enfermedad, conjuntamente con la difusión de una agenda de investigación pueda explicar el apoyo y la colaboración brindado por la $\mathrm{RF}^{76}$ a la experiencia mendocina, a la que también contribuyeron la Fundación Loomis y la Compañía Parke-Davis de Detroit (Michigan).

En segundo lugar, luego de la Segunda Guerra Mundial, Estados Unidos inició (tímidamente) acciones de propaganda destinadas a exaltar los usos pacíficos de la energía nuclear, que derivarían años más tarde en la campaña Átomos para la Paz. Así, en junio de 1947, el presidente Truman anunció que pondría isótopos radioactivos a disponibilidad de científicos extranjeros ${ }^{77}$. Según el periódico The Washington Post ${ }^{78}$, Argentina formaba parte de un programa que estableció la Comisión de Energía Atómica de los Estados Unidos para la exportación de isótopos radioactivos producidos en los laboratorios atómicos de Oak Ridge (Tennesse) y destinados al la para tratamiento de enfermedades, de allí provendrían los radioisótopos utilizados en Mendoza en 1951.

En el plano local, desde mediados de la década del 40, la energía nuclear también pasó a ocupar un lugar central en la agenda de gobierno, algunas de cuyas iniciativas incluían a la Universidad Nacional de Cuyo. En septiembre de 1945, se sancionó un decreto destinado a preservar los yacimientos de Uranio, a partir del cual dicha Universidad, junto con la Dirección General de Fabricaciones Militares, se hizo cargo de la prospección de uranio y torio. En 1950 fue creada la Comisión Nacional de Energía Atómica (CNEA), con el objetivo de dar soporte administrativo a las actividades de Richter en Bariloche $^{79}$. Un año más tarde, con el fracaso de éste último, se creó la Dirección

75 FAO/WHO (1949), Joint FAO/WHO Expert Committee on Nutrition Report of a meeting held 24-28 October 1949.

76 Debe destacarse el temprano interés de esta fundación en promover las investigaciones en medicina nuclear, que en 1940 instaló un ciclotrón en la Universidad de Washington para la producción de radioisótopos destinados a investigaciones médicas.

77 SANTESMASES, M.J. (2006), Peace propaganda and biomedical experimentation: influential uses of radioisotopes in endocrinology and molecular genetics in Spain (1947-1971), Journal of the History of Biology, 39, pp. 765-794, p. 772.

78 The Washington Post, 5 de septiembre de 1948

79 Ronald Richter era un físico austríaco graduado en le Universidad Alemana de Praga, que había sido colaborador de Manfred von Ardenne en Berlín durante la Segunda Guerra Mundial. Richter llegó en secreto a la Argentina en 1947, como parte de un grupo de ingenieros y técnicos alemanes liderados por el diseñador aeronáutico Kurt Tank. Se ha estimado que a fina- 
Nacional de Energía Atómica (DNEA) bajo dependencia del Ministerio de Asuntos Técnicos, que apuntó al entrenamiento de científicos y técnicos loca$\operatorname{les}^{80}$. Simultáneamente, se creó la Comisión Nacional de Radioisótopos ${ }^{81}$, a la que se le atribuyó la responsabilidad de promover y controlar el uso de los mismos. La colaboración brindada por estas instituciones a los estudios sobre bocio realizados en Mendoza permitió, por un lado, la obtención de todos los equipos electrónicos necesarios y, por otro, la importación semanal de radioisótopos provenientes de la división de investigaciones médicas de los laboratorios de Oak Ridge (Tennesse), dependientes de la Comisión Nacional de Energía Atómica de EE.UU ${ }^{82}$.

Por último, si bien la relación de Perón con la comunidad científica local, luego de la intervención de las universidades, fue bastante conflictiva ${ }^{83}$, debe destacarse que la Universidad Nacional de Cuyo fue señalada como «la primera del país que ha tomado un ritmo verdaderamente justicialista» y se constituyó en uno de los jalones de un proceso de organización y creación de instituciones que, en la retórica oficial, adquirieron dimensiones de una cruzada fundacional de la nueva «Argentina científica». En ese contexto fue creada, en 1950, la Facultad de Ciencias Médicas «Tomás Perón» dependiente de la Universidad Nacional de Cuyo, entre cuyas misiones estaba la resolución de problemas sanitarios de índole local/regional como el bocio endémi$\mathrm{co}^{84}$. El apoyo oficial brindado a los estudios realizados en el Instituto del

les de 1952, el gobierno había invertido en este proyecto más de 62 millones de pesos. Véase MAriscotti, M. (1985), El secreto Atómico de Huemul, Sudamericana, Buenos Aires, p. 225.

80 Hurtado DE MendozA, D. (2005), Autonomy, even regional hegemony: the hard way toward the first research reactor (1945-1958), Science in Context, 18 (2), pp. 285-308.

81 Decreto n. ${ }^{\circ} 15.571 / 50$.

82 El periódico Los Andes exaltaba, así, el apoyo y la colaboración directa del Ministerio de Relaciones Exteriores y de la Dirección Nacional de Energía Atómica del Ministerio de Asuntos Técnicos, organismo este último que «ha proporcionado equipos electrónicos que, por primera vez, se incorporan al tratamiento científico de la enfermedad» (Los Andes, 21 de junio de 1951, p. 3).

83 Sobre la relación entre Perón y la comunidad científica, véase HURTADO, D. y BuSALA, A. (2006), De la 'movilización industrial' a la 'Argentina científica': la organización de la ciencia durante el peronismo (1946-1955), Revista da Sociedade Brasileira de História da Ciência, 4 (1), pp. 17-33.

${ }^{84}$ El informe de la comisión encargada de estudiar el proyecto de creación de la facultad, se consignaba la necesidad de «obtener la especialización de los profesores, y substancial investigación, de las modalidades regionales, trasuntadas a través de manifestaciones patológicas de trascendencia social como el bocio...». Véase UNIVERSIDAD NACIONAL DE CUYO (1951), Revista de la Facultad de Ciencias Médicas de "Doctor Tomás Perón”, enero- abril, 1, p. 20. 
Bocio fue tal que las actividades del equipo argentino-norteamericano recibieron una amplia cobertura periodística, los radioisótopos y el equipamiento fueron trasladados de Buenos Aires a Mendoza por la Fuerza Aérea y los científicos norteamericanos se entrevistaron en dos ocasiones con el Presidente de la Nación ${ }^{85}$.

El corolario de la experiencia de cooperación internacional fue, en primer lugar, la instalación de una sección de Radioisótopos de la División e Instituto del Bocio ${ }^{86} \mathrm{y}$, en segundo lugar, la sanción de una ley provincial que establecía el uso obligatorio de sal yodada en porcentajes estipulados en base al nivel de deficiencia de la población. Desde entonces, el Ministerio de Asistencia provincial fue el organismo responsable de velar por la medida, y los análisis de yodo de la sal enriquecida quedaron a cargo de los laboratorios de Química de la División Bocio y del Instituto del Bocio de la Universidad Nacional de Cuyo.

En 1956 la Memoria Anual de la División e Instituto del Bocio de Mendo$z a$ evaluaba como satisfactorio el nivel de acatamiento de la norma por parte de los industriales de la sal ${ }^{87}$. Los números oficiales también parecían alentadores a la hora de mostrar los progresos sanitarios del programa institucional: calculando los 700.000 habitantes de la provincia mendocina y tomando como base que el consumo anual de sal por habitante era de $4 \mathrm{~kg}$, se deducía que «la casi totalidad de la población estaba consumiendo sal enriquecida» ${ }^{88}$. Por último, se constataba que los bocios eutiroideos (bocios con función normal de tiroides) de Mendoza habían subsanado casi completamente su déficit de yodo, lo que daba un margen de optimismo para conseguir una disminución sustancial del bocio endémico en la provincia.

85 Stanbury, J.B. (2004), Conferencia en Homenaje a la memoria del Prof. Dr. Héctor Perinetti (quinta parte), Revista Argentina de Endocrinología y Metabolismo, 41 (2).

86 Dicha Sección empleó, en 1956, 800 Mc de yodo radioactivo (I-131) y 140 Mc de fósforo radioactivo (P-32) enviados desde Gran Bretaña y suministrados por la Comisión Nacional de Energía Atómica para el estudio y tratamiento de los enfermos. Memoria anual de la División Bocio e Instituto del Bocio de Mendoza (año 1956), La Semana médica, 1957, n. ${ }^{\circ}$ 3324, pp. 181-183.

87 Según esta memoria, durante los años 1955 y 1956 en la provincia de Mendoza se habían vendido $9.356 .897 \mathrm{~kg}$. de sal común y $2.777 .914 \mathrm{~kg}$. de sal yodada y $9.319 .944 \mathrm{~kg}$. de sal común y $2.822 .680 \mathrm{~kg}$. de sal yodada respectivamente.

88 La Semana Médica (1957), p. 183. 


\section{EPÍLOGO: NUEVAS AGENDAS DE INVESTIGACIÓN}

Poco después de los estudios en Mendoza comenzó a concretarse el proyecto de «geomedicina» al que se refería el doctor Means. En diciembre de 1952, la OMS organizó en Londres una reunión con un grupo de especialistas en bocio endémico, con el objeto de coordinar visitas a diversos países de Asia y Sud América y estudiar la manera de proporcionar una profilaxis eficaz. Allí quedó constituido el Grupo de Estudio de la OMS sobre el Bocio Endémico - del que participaría Stanbury - que, por un lado, estableció una serie de recomendaciones para la realización de encuestas y la yodación de la sal (métodos, compuestos, cantidades, aspectos legales, etc) y, por otro, delineó una agenda de investigación: en clínica, en lo referido a la sal yodada y en estudios sobre el terreno ${ }^{89}$. Fue en ese contexto que los trabajos de Stanbury y Perinetti se constituyeron en referencia obligada.

También a fines de la década del 50, el comité consultor de la OPS eligió un grupo de enfermedades prioritarias en Latinoamérica, entre los que se encontraba el bocio endémico. Poco después, con el asesoramiento de Stanbury, fue instituido un programa de desarrollo de centros de investigación, se estimuló a un grupo científicos y médicos de diversos de países para que desarrollaran investigaciones y programas de prevención, dando así lugar a un grupo de especialistas latinoamericanos que durante años llevaron a cabo investigaciones, reuniones y publicaciones ${ }^{90}$.

En el plano local, el Instituto del Bocio de Mendoza sirvió de modelo para la posterior creación de instituciones similares en otras provincias, como el Instituto de Endocrinología y Nutrición creado por Arturo Oñativia - discípulo de Del Castillo - en Salta en 1957 y el Instituto del Bocio y la Nutrición de Chilecito (La Rioja), fundado por Mario Desio de la Vega en 1956. Pocos años después se creó la Comisión Nacional de Lucha contra el Bocio Endémico (1958), integrada por Bernardo Houssay, Enrique B. del Castillo, Héctor Perinetti, Arturo Oñativia, Eduardo Trucco, Alberto Houssay, Juan M. Allende, Carlos R. Bravo y Mauricio Rapoport ${ }^{91}$. De su acción y la de sus antecesores resultó, en 1967, la sanción de la Ley Nacional que establecía el uso obligatorio de sal yodada y que comenzaría a aplicarse en 1970.

89 Grupo de Estudios de la OMS SOBRE El BOCIO ENDÉMICO (1954), pp. 296-303.

90 STANBURY (2004), p. 3.

91 La elaboración del anteproyecto de creación de la comisión estuvo a cargo de Héctor Perinetti. Ver PerinetTi (1990), p. 529. 
Asimismo, los estudios realizados en Mendoza dieron origen a un nuevo campo de estudios, que surgió fuertemente ligado a la endocrinología: la medicina nuclear. Entre 1953 y 1955 la DNEA dictó los primeros cursos de radioisótopos para médicos y biólogos y un curso de defensa radiológica ${ }^{92}$. En junio de 1954, la revista Sanidad de Cuyo comentaba las conclusiones de las Jornadas del Bocio realizadas en Mendoza entre el 29 y el 30 de marzo, entre las que se mencionaba la necesidad de solicitar a la DNEA una más amplia disponibilidad de radioisótopos para diagnóstico y tratamiento, una mayor información acerca de las condiciones mínimas que deberían reunir los locales que trabajaran con radioisótopos, el equipamiento con el que debían contar (sus costos y vías de adquisición) y las condiciones para lograr la capacitación especializada de los médicos (cursos, becas, adscripciones, etc.).

Ese mismo año, la CNEA instaló tres equipos para captación de yodo radiactivo y medición de muestras de sangre en hospitales de Buenos Aires: Hospital Rivadavia, Hospital Rawson y Hospital Cínicas ${ }^{93}$. Asimismo, algunos de los investigadores que participaron de la experiencia llevada a cabo en Mendoza, realizaron en esa época estudios con yodo radioactivo: Alberto Houssay (Instituto de Semiología del Hospital Clínicas); Enrique B. del Castillo (Servicio de Enfermedades Endocrinas del Hospital Rivadavia); Vicente Cicardo, Juan Reforzo Membrives, Aldo Lanaro y López Verde (Centro de Investigaciones Tisiológicas del Hospital Tornú); Roberto J. Soto y Rodolfo Q. Pasqualini (Instituto Modelo de Clínica Médica Luis Agote del Hospital Rawson); José Solis (Servicio de Endocrinología del Hospital Ex Caridad de Rosario) $)^{94}$.

Este nuevo campo contribuyó a su vez a consolidar las investigaciones sobre la hormona tiroidea, al punto que, en 1967, la Asociación Argentina de Medicina y Biología Nuclear organizó en la Comisión Nacional de Energía Atómica el Primer Coloquio Argentino de Hormonas Tiroideas, del que participaron quienes cuatro años antes habían presentado sus estudios sobre bocio

92 Uno de los primeros cursos fue «Bases físicas para el uso de los Radiactivos» (1953), dictado por el Dr. Poggio de la Dirección Nacional de Energía Atómica en el Instituto de Medicina Experimental para el Estudio y Tratamiento del Cáncer. Ver Legajo 30742. Instituto de Medicina Experimental para el Estudio y Tratamiento del Cáncer (1922-1953). Archivo y Mesa de la Facultad de Medicina de la Universidad de Buenos Aires.

93 Degrossi, O.J. (s/f), Entrevista a O.J. Degrossi. En http://www.diagnosticojournal.com/spa /diagnostico/dia171/html/degrossi.htm (consultado el 11-4-2009).

94 CNEA (1955), Memoria Anual de los Centros Médicos Biológicos apoyados por la Comisión Nacional de Energía Atómica, Copia mecanografiada, Biblioteca de la Comisión Nacional de Energía Atómica, pp. 113-121, 132-136, 140-141. 
en el Congreso Argentino de Endocrinología y Metabolismo ${ }^{95}$. La publicación, en 1970, de un libro sobre bocio endémico por parte de tres especialistas de la Comisión Nacional de Energía Atómica ${ }^{96}$ muestra el impacto que tuvo la introducción de nuevas técnicas en la consolidación de esa línea de investigación.

\section{CONCLUSIÓN}

La cuestión que atraviesa todo el trabajo se refiere al entrecruzamiento de diversas lógicas, asociadas con la posibilidad de resignificar el conocimiento científico y médico en términos de medidas de prevención y tratamiento de la salud. En este sentido, la historia del bocio endémico resulta ilustrativa de estos procesos, en la medida en que pudimos poner en movimiento las diversas racionalidades intervinientes, así como su relación con el papel del estado que, en diferentes momentos, asume las interpelaciones como propias y pone en prácticas políticas públicas para su implementación.

Así, pudimos mostrar que, en un primer momento, y a pesar de que la etiología del bocio era aún objeto de controversia, los actores comenzaron a reclamar la atención pública sobre la cuestión, es decir, a pugnar por colocarla en la agenda pública de las cuestiones de salud. Este proceso que se despliega durante las primeras décadas del siglo XX (en parte análogo y en parte atravesado por los debates sobre la enfermedad de Chagas, como mostraron Kreimer y Zabala) ${ }^{97}$, es coincidente con la institucionalización de una comunidad de investigación experimental en el campo biomédico en el país. De hecho, personajes como Houssay, Kraus y Sordelli son los referentes de dicho proceso $^{98} \mathrm{y}$, por ello, el hecho de que sean ellos mismos quienes tematicen públicamente al bocio como «problema» — aunque ello no forme parte del núcleo de sus investigaciones - tiene un significado y unas consecuencias particulares: además del esperable efecto «legitimador» que provenía de lo «autorizado» de dichas voces, las consecuencias pueden ser analizadas en

95 CNEA (1967), La CNEA fue sede del Primer Coloquio Argentino de Hormonas Tiroideas, Boletín Informativo, 2, pp. 18-20.

96 Degrossi, O.J., Pecorini, V. y Altschuler, N. (1970), Bocio Endémico. Estudio de poblaciones indigenas del departamento de Huiliches, Provincia de Neuquén, República Argentina, CNEA.

97 KREIMER y ZABALA (2007).

98 Buch (2006); KreIMer, P. (2010) Ciencia y Periferia. Nacimiento, muerte y resurrección de la biología molecular en la Argentina. Aspectos sociales, políticos y cognitivos, Buenos Aires, EUDEBA; EsTÉBANEZ (1996). 
términos de las redes y ramificaciones que se fueron irradiando a partir de la institucionalización de las investigaciones biomédicas. De hecho, los discípulos formados en estas tradiciones se fueron estableciendo y/o referenciando en diversas instituciones, tanto en la ciudad de Buenos Aires como en diversas regiones del país (Rosario, Córdoba, Salta, Mendoza, etc.).

Particularmente interesante resulta la definición alternativa del bocio como «problema de investigación» o como «problema social», debido a las implicancias de ambas perspectivas en términos cognitivos y de modelos institucionales. Otro tanto puede decirse sobre el enfoque de la enfermedad como «problema social» y como «problema de salud». En el primer caso, su tratamiento debía movilizar a una red amplia de actores, liderados por el estado — nacional o provincial - entendiendo que la enfermedad no era el resultado de un mero fenómeno individual y fisiológico, sino de factores de orden social, económico, cultural. Por el contrario, la resolución de un «problema de salud» quedaba restringida - en esos años - a una resolución individual y «caso por caso» de los médicos con los pacientes. Los modos de intervención resultan, por lo tanto, directamente determinados por los modos en que las cuestiones - públicas o no- son formuladas públicamente y aceptadas por los otros actores ${ }^{99}$. En el caso del bocio endémico no resulta casual que la cuestión comenzara a dirimirse en términos de una intervención pública a partir de mediados de los años 40, cuando el gobierno de Perón, junto a su ministro de Salud Pública (Ramón Carrillo), instalara en forma fuertemente institucionalizada la intervención del Estado frente a los «problemas sociales vinculados con la salud pública». Como mostramos, la cuestión distaba de ser novedosa, ya que décadas antes había sido formulada por Alfredo Palacios, médico y legislador socialista, quien había sido uno de los pioneros en abogar por esta perspectiva. Lo que cambió entonces de un modo radical fue la concepción del estado acerca de su propio rol en estas cuestiones.

Al respecto, dos notas resultan salientes del proceso de instalación pública del bocio y de sus mecanismos de profilaxis: la primera de ellas está vinculada con la dimensión internacional. En efecto, de todos los desarrollos que se emprendieron a nivel internacional sobre el tema durante las primeras décadas del siglo XX, sobresalen las experiencias realizadas por James Means primero, y luego por John Stanbury en Boston. La relación que el médico mendocino Héctor Perinetti, estableció con ese grupo resultó crucial para el establecimiento de medidas efectivas de profilaxis. Como muchas veces en la historia de los desarrollos científico-tecnológicos, las innovaciones en el pla-

99 Kreimer y Zabala (2007). 
no local son originadas por viajeros que, a través de relaciones de «cooperación», utilizan esta vía para legitimar sus propias estrategias cognitivas frente a los otros actores locales.

El segundo aspecto, que en realidad recorre todo el texto, se refiere a que las dificultades para establecer una adecuada profilaxis del bocio endémico (más allá de factores político-institucionales) responden al espacio de lo técnico más que a lo estrictamente científico: una vez establecida la función del yodo, la cuestión central radica en establecer la mejor forma de dosificarlo, los alcances de dicha operación y, elemento crucial, establecer los niveles adecuados con los que dicha dilución debe prepararse.

Lo que resulta particularmente novedoso en este caso, es que el aporte innovador fundamental provino de un campo completamente inesperado para la época: la física nuclear, que había tenido un impulso crucial durante el desarrollo de la Segunda Guerra Mundial (asociada con el conocido Proyecto Mannhattan) y que, a su fin, se fue reconvirtiendo parcialmente hacia los usos pacíficos de los conocimientos. En la Argentina, la cuestión tuvo un rápido desarrollo, en parte como consecuencia del interés del gobierno de Perón por el desarrollo de un incipiente proyecto nuclear que, con un origen fallido y algo pintoresco, asociado con el físico Richter y la llamada experiencia de la Isla Huemul ${ }^{100}$, propulsó la creación de un organismo público para la investigación en física nuclear. Al mismo tiempo se estaba desarrollando, de un modo relativamente temprano, en relación con los países más avanzados, un nuevo campo de investigaciones y de prácticas experimentales: la medicina nuclear.

Para terminar, digamos que, como en el desarrollo científico-tecnológico de la mayor parte de los países periféricos, el papel de los organismos internaciones también debe ser tomado en cuenta, ya que a menudo es la vía a través de la cual se difunden y legitiman tomas de posición que habrán de ser, en lo sucesivo, cuestiones que pasan a formar parte de las agendas nacionales de políticas. En el caso que analizamos, el papel de la Organización Panamericana de la Salud y de la OMS no escapa a estas consideraciones. A menudo, el cruce entre investigadores de países periféricos y países centrales, en particular en el campo de la salud y de la investigación biomédica, se ve fertilizado por los espacios internacionales de estos organismos. Así, como señalamos, en la década del 50, la OPS eligió un grupo de enfermedades (cuyo estudio y tratamiento se considera prioritario para Latinoamérica), entre las que se encontraba el bocio endémico. Ello implicó que la temática se difundió

100 MARisCOTTI (1985). 
entre centros de investigación, investigadores y médicos de la región, impulsando el desarrollo de investigaciones, publicaciones y de espacios de socialización pública referidos a la enfermedad.

La intervención de todos estos actores, sus posicionamientos y concepciones acerca de la enfermedad, la puesta en marcha de diversas estrategias, alianzas, alineamientos, etc., en el marco de ciertos contextos institucionales e históricos, pone en evidencia un complejo entramado socio-cognitivo que atraviesa la relación entre la producción del conocimiento y su aplicación.

Fecha de recepción: 5 de mayo de 2009

Fecha de aceptación: 2 de febrero de 2010 